* Doutora em Direito pela Universidade de São Paulo (USP). Estudos de doutorado (bolsa CNpq) na J.W.Goethe Universitaet, Frankfurt. Possui estágio pós-doutoral na Ecole des Hautes Etudes en Sciences Sociales, Paris. Livre-docente pela Universidade de São Paulo (USP). Professora da Universidade Federal de Santa Catarina UFSC). Coordenadora do grupo de pesquisa Estudos Avançados em Meio Ambiente e Economia no direito Internacional. Pesquisadora CNPq. Email: cristiane.derani@ ufsc.br

** Mestranda do Programa de Pós-Graduação em Direito da Universidade Federal de Santa Catarina (UFSC) da área de concentração Direito, Estado e Sociedade; linha de pesquisa Direito, Meio Ambiente e Ecologia Política. E-mail: najodas@ gmail.com

\section{Pagamento por serviços ambientais (PSA) e a racionalidade ambiental: aproximações}

\author{
Payment for enVironmental Services (PES) \\ AND ENVIRONMENTAL RATIONALITY: \\ APPROXIMATIONS \\ * Cristiane Derani \\ ** Natália Jodas
}

Resumo: O presente trabalho tem o propósito de investigar se o Pagamento por Serviços Ambientais (PSA), em determinados formatos e contextos de desenvolvimento, pode servir à construção de uma racionalidade ambiental (Enrique Leff). Desse modo, discute-se, inicialmente, os instrumentos econômicos estatais de gestão ambiental que visam corrigir as falhas do mercado para, na sequência, discorrer sobre os distintos padrões dos programas de PSA executados no Brasil. Questiona-se, nesse contexto, se o PSA estaria vinculado a uma política de valoração econômica da natureza ou se, em certos cenários, consistiria em incentivo econômico. Reflete-se, ao final, a possibilidade de aproximação do PSA às concepções de uma racionalidade ecológica, a partir de pressupostos edificados ao longo da pesquisa. A metodologia adotada é a revisão bibliográfica da literatura jurídica vinculada à temática, bem como a análise documental indireta, de relatórios institucionais produzidos por instituições públicas e privadas.

Palavras-chave: Instrumentos econômicos; Pagamento por serviços ambientais; Valoração ambiental; Incentivo economic; Racionalidade ambiental.

Abstract: This study aims to investigate if the Payment for Environmental Services (PES), in some formats and contexts of development, can help building environmental rationality (Leff). In this light, the initial of the essay are the economic instruments of environmental management aimed at correcting market failures. In sequence, the different patterns of PES programs in Brazil are analyzed. In this context, it is argued if PES is chained to a policy of environmental precification (in a monetary sense) or if PES is an economic incentive (positive sanction). Towards the end of the present article, it is argued about a possible approximation of PES and the concepts of ecological rationalization. The methodology used in this article is based in literature review and document analysis.

Keywords: Economic instruments; Payment for environmental services; Enviromental evaluation; Economic incentive; Environmental rationality. 


\section{INTRODUÇÃO}

Ao longo da última década, os instrumentos econômicos de gestão e conservação do meio ambiente têm sido implementados em maior grau no Brasil. $\mathrm{O}$ aumento da densidade populacional somado à ocupação irregular urbana, à extensão das fronteiras agrícolas e ao uso descontrolado dos recursos naturais enfatizou, de certa forma, a falibilidade das ferramentas de comando e controle do Estado.

Os incentivos econômicos, como elementos integrantes da regulação ambiental estatal, foram delineados na Declaração do Rio de Janeiro de 1992 (artigo 16) e tiveram o escopo de reduzir os custos resultantes do cumprimento da legislação, baixar os encargos administrativos do setor público e influir na tomada de decisão e na conduta dos agentes econômicos por meio de estímulos.

O Pagamento por Serviços Ambientais (PSA), tipologia econômica de gerência ambiental, propagou-se nas diferentes regiões do país, com a finalidade de "resolver" problemas específicos locais. Ainda que não haja um marco legal federal regulamentador do instituto, diversas são as experiências com o PSA e distintos os formatos e modelos do seu desenvolvimento.

Com a finalidade de realçar as peculiaridades e distinções existentes entre os programas de Pagamento por Serviços Ambientais (PSA) em execução no Brasil, a presente pesquisa sublinha a necessária diferenciação existente entre os projetos de PSA, de acordo com sua instituição idealizadora, provedores dos serviços ambientais (público-alvo), objeto, termos de compromissos, entre outros, para, mais à frente, desconstruir a crítica generalizada de que o instrumento seja um elemento do mercado desconstituído de vieses ecológicos.

Na primeira parte, discorre-se acerca dos instrumentos de regulação estatal criados para corrigir as constantes falhas do sistema econômico, destacando, de um lado, as ferramentas de comando e controle e, de outro, os aparelhos econômicos.

$\mathrm{Na}$ sequência, examina-se com maior profundidade o Pagamento por Serviços Ambientais (PSA), de modo a esmiuçar seus possíveis atores e agentes sociais, tipologias e características do instituto a depender do contexto e realidade abordados.

Elucidados aspectos da valoração econômica do meio ambiente, refletese, ao final, sobre a possibilidade de aproximação do PSA às concepções de uma racionalidade ambiental, tal como sustentado por Enrique Leff. 
O trabalho utiliza como metodologia a revisão bibliográfica da literatura jurídica vinculada à Economia (Arthur Pigou e Ronald Coase) e ao Direito Ambiental, bem como a análise documental de relatórios institucionais produzidos por instituições públicas e privadas relacionadas aos programas de Pagamento por Serviços Ambientais.

\section{INSTRUMENTOS ECONÔMICOS ESTATAIS DE PROTEÇÃO AMBIENTAL}

\subsection{A correção das falhas do mercado}

Os instrumentos regulatórios sobre o uso da natureza ampliaram-se no âmbito dos Estados a partir da segunda metade do século XX, especificamente, com a publicação do Relatório de Meadows (1972) e a Conferência de Estocolmo (1972). Esses marcos internacionais foram propulsores de um novo sistema de controle ambiental, composto por normas, regulamentos e regras de conduta sobre o ambiente (MOTA, 2001, p. 124).

A necessidade de controle estatal sobre a utilização dos recursos naturais deveu-se, principalmente, à percepção da finitude dos ecossistemas terrestres, e, de outro lado, à assimilação direta dos efeitos adversos causados pelas atividades humanas aos biomas (poluição difusa, catástrofes naturais). O Direito Econômico procurou coadunar o sistema produtivo ao bem-estar social, e o Direito Ambiental dispôs-se a rever e redimensionar conceitos sobre a convivência das atividades sociais com a proteção da natureza, de modo que ambos elencaram a política econômica como sua fonte fundamental de atuação (DERANI, 1997, p. 71).

É certo que as atividades econômicas geram efeitos externos prejudiciais à sociedade (deseconomias externas negativas), e nem todos os custos socioambientais oriundos do processo produtivo são acoplados aos preços do produto final. O cálculo mercantil é incompleto, o que leva, segundo A. C. Pigou, a uma inevitável utilização subotimizada da natureza e, consequentemente, a uma perda de bem-estar (ALTVATER, 1995, p. 140).

O exemplo clássico da falha de mercado é a poluição causada na execução de determinado bem. Uma indústria que lança efluentes sobre um curso d' água, causando, consequentemente, a piora da qualidade da água e o aumento dos cursos de tratamento do recurso pela coletividade, não compensa tais perdas, pois estas circulam à margem do mercado (NUSDEO, 2006, p. 359). A percepção equivocada de que os recursos ambientais sejam bens livres 
destituídos de escassez contribui para seu uso excessivo e desmesurado, intensificando a crise ecológica do planeta.

Ensina Altvater (1995, p. 141-146):

Efeitos externos, contudo, desempenham algum papel apenas quando são sentidos e conhecidos pelos atores do mercado. Isto não acontece enquanto os efeitos da externalização de custos privados são "engolidos pelo bem coletivo"e, por isso, não aparecem no cálculo de custos de outros agentes privados. [...] Nesses termos, a capacidade de sentir e conhecer os efeitos externos tem a ver com o modo de percepção das transformações da natureza. [...]. Precisamos nos dedicar em primeiro lugar às externalizações negativas (sobretudo os prejuízos ao ambiente natural), às deseconomias externas.

Embutir os "custos sociais" na cadeia produtiva significa refletir sobre uma variedade de despesas. De fato, os "custos sociais" envolvem todas as perdas diretas e indiretas sofridas por terceiros e pelo público geral por consequência das atividades privadas de mercado. As perdas sociais podem implicar danos à saúde humana, a destruição ou deterioração dos valores da propriedade e a diminuição do patrimônio natural (KAPP, 1950, p. 13).

Nesse caminho, as concepções defendidas pelos economistas liberais clássicos passam a ser debatidas pelas teorias de Arthur C. Pigou (1959) (The Economics of Welfare - 1920) e Ronald H. Coase (1960), as quais propuseram a correção das externalidades negativas ("custos sociais") na esfera econômica, ainda que em formatos distintos. O primeiro sustentou a atuação do Estado na economia, com vistas a corrigir o desequilíbrio do mercado em relação à utilização dos ecossistemas (tributos/ "imposto pigouviano") e para que o Poder Público pudesse "agir subsidiariamente com os custos dos efeitos externos." (DERANI, 1997, p. 112).

Por outro viés, o segundo economista, mais liberal, advogou que a negociação entre os agentes econômicos, concorrentes pelo mesmo recurso natural, levaria a um nível ótimo de emissão de externalidades, consolidado por meio de acordos de internalização. O teorema de Coase entende que todos os bens podem ser objeto de apropriação privada (property rights), sobre os quais recairia a exclusividade de uso e a trasmutabilidade dos bens ambientais (MONTERO, 2011, p. 101).

As ideias de Pigou e Coase colaboraram à inserção dos aspectos sociais e ecológicos no âmbito das ciências econômicas. Por essa razão, pode-se afirmar que as teses construídas por estes doutrinadores cooperaram à evolução dos 
mecanismos e instrumentos de gestão ambiental utilizados pelas nações na atualidade.

\subsection{Instrumentos regulatórios em matéria ambiental}

Os efeitos nocivos decorrentes da depreciação dos biomas naturais acarretaram a necessidade de intervenção estatal nas relações econômicas, com vistas a corrigir as falhas e disparidades provocadas à coletividade. Por esta razão, as políticas públicas ambientais têm a finalidade de induzir a internalização das externalidades ambientais (negativas ou positivas) pelos agentes econômicos (MONTEIRO, 2011, p. 110).

O Estado assume o papel de regulador das atividades capitalistas para enfrentar os problemas ambientais oriundos das mesmas. Aragão (2004, p.37) elucida que:

[...] regulação estatal da economia é o conjunto de medidas legislativas, administrativas e convencionais, abstratas ou concretas, pelas quais o Estado, de maneira restritiva da liberdade privada ou meramente indutiva, determina, controla ou influencia o comportamento dos agentes econômicos, evitando que lesem os interesses sociais definidos no marco da Constituição e orientando-os em direções socialmente desejáveis.

Durante as décadas de 70 e 80 , o sistema de comando e controle, isto é, as medidas de planificação e de punição estatais foram predominantes nas políticas internas dos países (FOLADORI, 2001, p. 144). A estrutura de comando e controle baseia-se na imposição de standards, limites, padrões e proibições sobre as ações consideradas lesivas ao meio ambiente.

No Brasil, a Constituição Federal de 1988 (art. 225) e a Lei da Política Nacional do Meio Ambiente (LPNMA) - Lei nº. 6.938/1981 -, destacam-se, entre a vasta legislação ambiental, por aventarem pioneiramente as diretrizes, princípios e parâmetros sobre o uso sustentável do ambiente. Nesse caso, sublinha-se a exigência de licenças e autorizações ambientais para a construção, instalação, ampliação e funcionamento de estabelecimentos e atividades utilizadores de recursos ambientais (art. 10, LPNMA); a necessidade de estudo prévio de impacto ambiental (EPIA-RIMA) para instalação de obra ou atividade potencialmente causadora de significativa degradação do meio ambiente (art. $\left.225, \S 1^{\circ}, \mathrm{IV}, \mathrm{CF}\right)$; o estabelecimento de padrões de qualidade ambiental (art. $9^{\circ}$, I, LPNMA); o zoneamento ambiental (art. $9^{\circ}$, II, LPNMA), entre outros. 
É válido registrar que os mecanismos de comando e controle possuem deficiências, sem as quais as ferramentas econômicas de regulação não teriam espaço para existir. Nesse particular, aponta-se o elevado custo administrativo das autoridades governamentais no monitoramento do cumprimento das obrigações e deveres estabelecidos nas normativas ambientais e o risco de fomentar-se um "mercado" de corrupção (CAMPOS, 2011, p. 292).

De outra banda, os instrumentos econômicos passam a ser introduzidos nas plataformas políticas a partir dos anos 90. A Declaração do Rio sobre o Meio Ambiente (Rio 92) delineou no seu artigo 16 as linhas do princípio do poluidor pagador, estimulando, conjuntamente, a utilização das ferramentas econômicas, a saber:

As autoridades nacionais devem procurar promover a internalização dos custos ambientais e o uso de instrumentos econômicos, tendo em vista a abordagem segundo a qual o poluidor deve, em princípio, arcar com o custo da poluição, com a devida atenção ao interesse público e sem provocar distorções no comércio e nos investimentos internacionais (ORGANIZAÇÃO DAS NAÇÕES UNIDAS, 1992).

O objetivo dos mecanismos econômicos é "incentivar aqueles que ajudam a conservar ou produzir serviços ambientais a conduzirem práticas cada vez mais adequadas que assegurem a conservação e a restauração dos ecossistemas" (MMA, 2014). Nessa categoria situam-se as medidas de apoio ou ajudas financeiras, os sistemas de depósito/reembolso, a criação de mercados e tributos (MONTEIRO, 2011, p. 118).

Os instrumentos econômicos atuam por meio de um sistema de incentivos e desincentivos, econômicos ou fiscais, estabelecendo vantagens ou impondo ônus (principalmente de caráter tributário) (MONTEIRO, 2011, p. 116). No território brasileiro, citam-se como meios econômicos de gerenciamento dos recursos naturais: a cobrança pelo uso da água (art. $5^{\circ}$, IV, Lei $n^{0} .9 .433 / 1997$ ); o ICMS ecológico (Imposto sobre Circulação de Mercadorias e Serviços - art. 155, II; 158, IV, CF/88); o Pagamento por Serviços Ambientais (PSA - artigos 58, VIII e 41, I, da Lei $n^{\circ} .12 .651 / 2012$ ); Seguros Ambientais (art. 9 ${ }^{\circ}$ XIII, Lei $n^{\circ} .6 .938 / 1981$ ); taxas florestais; concessão florestal (art. $9^{\circ}$, XIII, Lei nº.6.938/1981); servidão ambiental (art. XIII, Lei n $\left.{ }^{\circ} .6 .938 / 1981\right)$; royalties, entre outros.

As vantagens atribuídas aos instrumentos econômicos são a possibilidade de redução dos gastos decorrentes do cumprimento da legislação e dos encargos 
administrativos do setor público, além de configurarem alternativa economicamente eficiente e ambientalmente eficaz a complementar as abordagens de comando e controle (CAMPOS, 2011, p. 296).

Enfatiza-se, noutra ótica, a crítica direcionada aos incentivos econômicos, no sentido de que estes ainda não foram comprovados pela experiência prática, sendo que seus objetivos podem ser eventualmente desvirtuados e tornarem-se contraditórios, trazendo, como consequência, a necessidade de controle governamental (CAMPOS, 2011, p. 296).

De certo modo, pode-se dizer que a implementação de apenas uma destas tipologias de ingerência estatal não parece ser suficiente a promover a tutela efetiva do bem ambiental.

No que diz respeito às ferramentas de controle, por exemplo, é sabido que a falta de estrutura e desamparo dos órgãos ambientais de fiscalização permitiram a ineficácia de importantes arcabouços legais, tais como o Código Florestal (antiga Lei $n^{\circ} .4 .771 / 1965$ ), a lei de crimes ambientais (Lei ${ }^{\circ} .9 .605 /$ 1998), entre outros. A consequência acaba sendo o recorrente apelo aos Tribunais que, muitas vezes, não resguarda a devida proteção ao meio ambiente. Por outro lado, o emprego único e desmedido de instrumentos econômicos pode gerar suscetibilidade à lógica individualista e mecanicista da racionalidade mercadológica.

Em sendo assim, discorre-se, no tópico seguinte, sobre o Pagamento por Serviços Ambientais (PSA), espécie de instrumento econômico ecológico, com a finalidade de costurar, mais à frente, considerações sobre a aproximação de uma racionalidade ambiental a partir de determinados contextos.

\section{PAGAMENTO POR SERVIÇOS AMBIENTAIS (PSA)}

\subsection{Conceito e características}

Ao longo da última década, os instrumentos econômicos de gestão e conservação do meio ambiente têm sido implementados em maior grau no Brasil. $\mathrm{O}$ aumento da densidade populacional somado à ocupação irregular urbana, à extensão das fronteiras agrícolas e ao uso descontrolado dos recursos naturais realçou a incompletude das ferramentas de comando e controle do Estado.

O Pagamento por Serviços Ambientais (PSA), tipologia econômica de gerência ambiental, propagou-se nas diferentes regiões do país de maneira inédita, com a finalidade de "resolver" problemas específicos locais. Ainda que não haja um marco legal federal regulamentador do instituto, diversas são as 
experiências com o PSA e distintos os formatos e modelos do seu desenvolvimento.

Primeiramente, importa diferenciar os serviços ecossistêmicos dos ambientais. Os primeiros designam os serviços prestados pelos ecossistemas, a exemplo da purificação do ar, ciclo hidrológico, polinização, provisão de alimentos, regulação do clima, etc. Enquanto que os últimos são utilizados para denominar as atitudes ambientalmente desejáveis, ou seja, aquelas que contribuem para a concretização das externalidades positivas (ALTMANN, 2012, p. 307).

Em outras palavras: os serviços ecossistêmicos são os benefícios gerados pela natureza independentemente da atuação do homem. Ao passo que os serviços ambientais dizem respeito às iniciativas humanas que favorecem e fomentam a oferta dos serviços ecossistêmicos.

Os serviços ambientais prestados por um agricultor, por exemplo, figurarse-iam por meio do cercamento e preservação de suas áreas protegidas (matas ciliares, nascentes, topos de morros), pelo não depósito de efluentes no curso d' água (esgoto, agrotóxicos) e pela implementação de boas práticas agrícolas. Consequentemente, a médio e longo prazo, a sociedade teria como resultado melhorias na qualidade das águas, do ar, dos alimentos, entre outros (serviços ecossistêmicos).

O princípio do protetor-recebedor é o fundamento máximo do Pagamento por Serviços Ambientais (PSA), em vista de que sua essência seja impulsionar condutas sustentáveis para que os comportamentos promovidos possam conservar e manter, indiretamente, os serviços ecossistêmicos almejados.

Assim, o Pagamento por Serviços Ambientais (PSA) pode ser definido como as "transações entre duas ou mais partes envolvendo a remuneração àqueles que promovem a conservação, recomposição, incremento ou manejo de áreas de vegetação considerada apta a fornecer certos serviços ambientais (NUSDEO, 2012, p. 69).” As metodologias ambientais empregadas variam conforme a realidade local e são determinantes a tornar efetiva a pretensão planejada.

O PSA tem como características o fato de que "os beneficiários dos serviços ambientais pagam, de maneira direta, contratual e condicionada aos proprietários e usuários locais por adotar práticas que assegurem a conservação e restauração dos ecossistemas." (WUNDER, 2006, p. 1). Ressalta-se que o PSA deve ser necessariamente voluntário e não depende obrigatoriamente de um recebimento pecuniário, conforme esclarecem Waldman e Elias (2013, p. 56): 
O pagamento não se restringe à pecúnia, mas pode envolver outros benefícios diversos como isenção fiscal (taxas e impostos), benfeitorias, acesso facilitado a mercados, programas especiais e concessão de linhas de crédito, disponibilização de tecnologia e capacitação.

Indicam-se como exemplos de transações voluntárias e não monetárias a construção de açudes, mudas de espécies frutíferas, insumos para a construção de galinheiros (LAVRATTI, 2014, p. 103), implementação de saneamento ambiental (biodigestores) (EXTREMA, 2010, p. 8), entre outros.

O PSA, desenvolvido pioneiramente na Costa Rica e em diversos países do continente americano, inverte a lógica até então prevalecente no sistema capitalista, já que o reforço está em otimizar e valorizar a paisagem natural, a biodiversidade, a qualidade da água, a regulação das chuvas, o controle das enchentes, recursos que, na ordem econômica, são tratados como inesgotáveis (IRIGARAY, 2004, p. 56).

\subsection{Tipologias}

Evidenciam-se, atualmente, quatro tipos de serviços ambientais estimulados nos programas de PSA, sendo eles: a) Sequestro e armazenamento de carbono (pagamentos para o plantio e manutenção de árvores/promoção da neutralização do carbono); b) proteção da biodiversidade (incentivos para proteger e restaurar áreas para criação de corredores ecológicos); c) proteção de bacias hidrográficas (estímulos a servidores situados nas cabeceiras dos rios para que reduzam a deflorestação, a erosão do solo e os riscos de inundação, por meio da preservação das matas ciliares e topos de morros); d) beleza cênica (fomento ao turismo de observação de vidas silvestres) (WUNDER, 2006, p. 2).

Os programas de PSA podem partir de iniciativa pública, em que a instituição governamental ou unidade administrativa atua como compradora, intermediadora ou facilitadora dos serviços ambientais (WALDMAN; ELIAS, 2013, p. 56). Neste formato, o projeto depende de regulamentação normativa para viabilizar a destinação dos recursos orçamentários públicos. Nada impede que um projeto de PSA liderado e gerido pelo Estado seja suplementado por patrocínios advindos da iniciativa privada.

Da mesma maneira, os projetos de PSA podem ser criados e coordenados na esfera particular, tendo como compradores as empresas privadas, terceiros, doadores, organizações não-governamentais ou órgãos e agências de cooperação nacional e internacional (WALDMAN;ELIAS, 2013, p. 56). 
Os provedores dos serviços ambientais, responsáveis pela promoção de mudanças de comportamento nos espaços geográficos, perfazem público variável, a depender da contrapartida (biodiversidade/bacia hidrográfica/ sequestro de carbono/beleza cênica) previamente definida na transação voluntária. Assim, os provedores dos serviços ecológicos diversificam-se de acordo com o contexto do programa de PSA, podendo ser comunidades tradicionais, indígenas, pequenos e médios proprietários, ou mesmo grandes proprietários rurais.

\subsection{Multiplicidade de formatos e experiências}

Foi na década de 90 que emergiram as primeiras iniciativas de PSA. Países como a Costa Rica (1996), pioneira por possuir um sistema de taxação do consumo de gasolina e água, e, posteriormente, os Estados Unidos, Japão, México e Equador consolidaram práticas de PSA em seus territórios (WALDMAN; ELIAS, 2013, p. 54).

Sublinha-se que em 2005 o Comitê do Meio Ambiente, tocante à análise dos objetivos acordados na Cúpula do Milênio, debruçou-se à temática dos serviços ecossistêmicos (NUSDEO, 2014, p. 415). Na última década, tem sido recorrente a execução de políticas públicas voltadas à remuneração dos serviços ambientais prestados por distintos públicos.

Antes mesmo da aprovação de uma lei federal regulamentadora do instituto, alguns estados brasileiros capitanearam projetos de PSA em seus territórios. Até o final de 2010, pelo menos 7 (sete) entes federativos já haviam aprovado leis sobre a matéria, são eles: Amazonas, Acre, Espírito Santo, Minas Gerais, Paraná, São Paulo e Santa Catarina (LAVRATTI, 2014, p. 17).

Esse quadro significativo e complexo de experiências demonstrou que os protótipos dos programas de PSA diversificaram-se entre os estados e, internamente, no âmbito dos municípios. Nesse ponto, a variabilidade das estruturas de PSA, mutáveis de acordo com a região e comunidades envolvidas, fez com que a doutrina e literatura jurídicas, em geral, construíssem de modo genérico a defesa e a crítica do instrumento. Na perspectiva de cotejar uma análise mais concreta sobre o instituto em apreço, colacionando-se os seus aspectos positivos e negativos no que se refere à qualidade ambiental e à mudança social, é relevante trazer à teoria jurídica elementos mais sólidos dessas vivências.

As diferentes combinações entre os objetos definidos no programa (serviços ambientais a serem ofertados) com os provedores da transação (público 
alvo) são os principais aspectos distintivos entre os esquemas de PSA no Brasil. Não se pode analisar de forma igualitária um esquema de PSA de sequestro de carbono direcionado a grandes propriedades rurais com um PSA de preservação de bacias hidrográficas aplicado a agricultores familiares, por exemplo.

Em geral, os PSAs vinculados à estocagem de carbono $\left(\mathrm{CO}^{2}\right)$ têm o predomínio de compradores privados e fornecedores de médio e grande porte (NUSDEO, 2012, p. 150), enquanto que os PSAs de conservação de águas e biodiversidade têm o Poder Público como comprador e as comunidades tradicionais e pequenos proprietários como provedores. Ainda assim, projetos de PSA com propostas ambientais semelhantes (por exemplo, preservação dos mananciais hídricos) podem apresentar abordagens e objetivos ecológicos distantes.

É certo que cada contexto de criação, contrato ou termo de compromisso, instituição idealizadora e viés propositivo são decisivos a proporcionar resultados ambientais significativos e permanentes, e melhores níveis de sensibilização ecológica junto dos atores envolvidos. Nesse sentido, relevante discutir se o PSA, em determinadas realidades, pode ser enquadrado como incentivo econômico e não como elemento de mercado, como difundido muitas vezes pela teoria econômica e ambiental.

\section{PAGAMENTO POR SERVIÇOS AMBIENTAIS (PSA): INCENTIVOS ECONÔMICOS OU MERCADOS?}

\subsection{PSA e a Valorização Econômica Ambiental}

A valoração econômica ambiental tem o escopo de examinar o valor econômico de um recurso ambiental por meio da determinação do que seja equivalente. Sua importância está em "estimar os custos sociais de se usar recursos ambientais escassos ou, ainda, incorporar os benefícios sociais advindos do uso desses recursos." (ORTIZ, 2003, p. 82).

A valoração ambiental contribui à ideia de gestão e decisão sobre atividades, usos, obras e projetos que causem impactos à natureza. Esta tarefa está longe de ser fácil, já que seu exercício depende de dados e recursos disponíveis, de métodos de valoração adequados, entre outros fatores. A valoração financeira de um serviço ambiental encontra dificuldades de mensuração pela subjetividade dos parâmetros que os envolvem, posto que não seja palpável atribuir valores econômicos padronizados expressos em dinheiro a todas as funções do ecossistema (WALDMAN; ELIAS, 2013, p. 57). 
As pretensões de atribuir valores monetários aos serviços e às perdas ambientais têm sua contribuição, porém, seu eixo principal deve ser, mais precisamente, o "desenvolvimento de indicadores e referências físicas de (in) sustentabilidade." (ALIER, 2014, p. 45). Na verdade, a valoração econômica do ambiente serve para alimentar o debate sobre como "levar em conta a natureza" no círculo da economia.

No campo do Pagamento por Serviços Ambientais (PSA), respalda-se que, em muitos casos, o valor pago ao provedor pelo PSA não exprime o "custo" do serviço ecossistêmico (água, regulação do clima, purificação do ar, fixação do carbono, alimentação, recursos genéticos, entre outros), mas a quantia atinente à conduta induzida no ator social (provedor). Nesse raciocínio, Altmann (2012, p. 319):

O pagamento se dá, portanto, não pelo serviço ecossistêmico em si (provisão de água, ciclo hidrológico, fixação de carbono), mas pela conduta do agente que garante o fluxo do serviço ecossistêmico. Com isso, a externalidade positiva é internalizada pelo mercado. Isso decorre de uma razão obvia: não se poderia pagar para o ecossistema. O pagamento somente é possível entre pessoas, físicas ou jurídicas. Por isso a doutrina aponta como natureza jurídica do PSA a remuneração pela conduta de preservar (grifo nosso).

A tarefa de balizar se as cifras que as instituições públicas ou privadas pagam aos serviços ambientais são baixos, justos ou altos não é simples, haja vista que o "custo ambiental não encontra valoração pecuniária correspondente, em razão de o pagamento estar direcionado a um bem intangível." (SERRÔA DA MOTA apud WALDMAN; ELIAS, 2013, p. 57). Isso pode explicar o porquê de o montante atribuído nos programas de PSA ser variável de acordo com o local e tipologia.

A título de exemplo, o Projeto "Conservador das Águas" de Extrema/ MG, pioneiro na publicação da lei regulamentadora de PSA (Lei municipal $n^{\circ}$. 2.100/2005), utiliza como valor de referência 100 unidades fiscais de Extrema (UFEX) por hectare ano, o que corresponde a cerca de R $\$ 152,00$ hectares/ano (PADOVEZI; DIEDERICHSEN; VEIGA, 2011, p. 51). Enquanto que o "Projeto Oásis", desenvolvido no município de Apucarana/PR e instituído pela Lei municipal $n^{\circ}$. 058/2009, realiza o pagamento mensal aos proprietários rurais de acordo com a vazão da nascente, sendo atribuído o valor mensal de até 03 unidades fiscais do município para cada nascente preservada (art. $4^{\circ}, \S 2^{\circ}$ ). 
No caso de Extrema/MG, a valoração dos serviços ambientais utilizou como cálculo o custo de oportunidade da terra, ou seja, o ganho dos produtores rurais com o gado leiteiro, em vista de que a diminuição da área de pastagens (principal atividade econômica), em razão da proteção das matas ciliares e topos de morros, acarretou a diminuição das cabeças de gado e, consequentemente, na produção de leite (PADOVEZI; DIEDERICHSEN; VEIGA, 2011, p. 50).

Em Apucarana/PR, o Decreto Municipal no. 076/2010 estabeleceu os valores a serem pagos aos proprietários dos imóveis urbanos e rurais enquadrados no Programa do "Projeto Oásis", sendo que, quanto maior o índice de preservação ambiental do espaço privado (antes de adentrar ao projeto), maior o valor recebido em termos de PSA.

Verifica-se que, conforme o contexto do projeto de PSA, a valoração econômica ambiental pode auxiliar no processo de análise do custo de oportunidade, em termos de aferição não exercida pelo provedor do serviço ambiental. Nesse raciocínio, desmistifica-se, em certa medida, a crença de que o PSA venha a ser o principal instrumento de monetarização da natureza.

Com esse raciocínio, importa refletir se o instituto poderá, a depender da realidade e experiência local, aproximar-se de uma racionalidade ambiental.

\subsection{Incentivos Econômicos e Racionalidade Ambiental: aproximações}

Feitas breves elucidações sobre a multiplicidade dos desenhos de PSA no Brasil e a necessidade de a doutrina jurídica achegar-se concretamente às experiências locais, relevante indagar se, no âmbito de alguns programas existentes, o PSA poderia ser considerado um incentivo econômico vinculado a uma proposta de racionalidade ambiental.

A princípio, enfatiza-se que os modelos de PSA comandados ou necessariamente intermediados pelo Poder Público inclinam-se a melhor "controlar" a tendência econômica de criar-se demanda de serviços ambientais por meio da criação de mercados. No mesmo caminho, descreve Nusdeo (2012, p. 22):

A alteração da característica de bem público da preservação ambiental, embora decorrente da análise neoclássica, não implica necessariamente a criação de demanda pela prestação de serviços ambientais por meio da criação de mercados. A criação de títulos individuais representativos da conservação pode ser feita no âmbito até mesmo de programas públicos de pagamento a proprietários e posseiros pela conservação florestal. Assim, deve-se evitar o 


\section{equívoco de confundir o uso da análise da economia ambiental quanto à estrutura de incentivos para a preservação com os instrumentos jurídicos baseados em mercados sobre direitos decorrentes da preservação (grifo nosso).}

São comuns os projetos em que a comunidade local (agricultores familiares/pequenos proprietários rurais/indígenas/ quilombolas/ etc) recebe o PSA pela preservação das matas ciliares, reservas florestais e biodiversidade sem que haja concorrência entre seus semelhantes ou mesmo interesses na "venda" dos serviços ambientais prestados.

Dentre os aspectos distintivos do PSA em relação aos mercados, destacase o fato do serviço ambiental, na medida em que seja um bem público e coletivo, induzir que os beneficiários dessa provisão não paguem necessariamente pelos mesmos, circunstância alheia à lógica mercadológica. Noutro ponto, pode-se afirmar que os mercados pressupõem uma interação espontânea dos agentes compradores e fornecedores, "cujo objetivo principal seja a alocação eficiente de recursos para a produção de bens e serviços cuja necessidade é variável e sinalizada pelo mercado" (NUSDEO, 2012, p. 70), o que dificilmente se averigua no PSA.

Outro fator considerado decisivo nesta diferenciação é presença de alguma forma contratual, ainda que configurada num termo de compromisso, na esfera do PSA. A dependência de uma estrutura regulatória que incite as transações dos serviços ambientais, bem como a predominância de objetivos socioambientais e não de mera eficiência alocativa é definitiva na distinção com a política mercadológica (NUSDEO, 2012, p. 70).

Somado a isso, o fato de o comprador do serviço ambiental (Poder Público/ empresas privadas/outros) assumir a obrigação de promover os pagamentos nas quantias e periodicidade definidos e ter o direito de fiscalizar e monitorar continuamente a execução dos compromissos firmados demonstra traços nítidos da natureza jurídica das transações (NUSDEO, 2012, p. 71) e não de um mercado maduro e fechado.

Negado o viés mercadológico do PSA quando formatado em contextos em que o Estado incentiva diretamente a comunidade a promover hábitos e comportamentos produtivos mais conectados à preservação do meio ambiente, é razoável admitir que a associação do PSA à condução de boas práticas agrícolas, ao uso sustentável da terra, à sensibilização ecológica da comunidade envolvida para a preservação ecossistêmica e a orientação crítica sobre o modelo 
agrícola hegemônico da atualidade (monoculturas/agrotóxicos) poderia representar um instrumento em busca de uma nova economia, rearticulada com a natureza.

Nesse quesito, um sistema de PSA que fomente a pluralidade, fortaleça a economia local e familiar e implemente um pensar ecológico capaz de modificar práticas prejudiciais aos biomas, certamente se aproxima de uma racionalidade esverdeada. Como defende Leff (2010, p. 32):

A nova economia deve basear-se em uma rearticulação entre cultura e natureza, ou seja, na capacidade criativa do ser humano, na produtividade cultural associada à produtividade ecológica do planeta e de cada um dos ecossistemas. Sobre essas bases será possível desarticular uma globalização uniforme, homogênea, guiada pela lei hegemônica do mercado, para construir outro processo civilizatório, fundado em uma diversidade de economias locais articuladas - que podem muito bem intercambiar excedentes econômicos -, fundamentadas nos princípios, valores e sentidos de uma racionalidade ambiental.

A concepção de PSA como ferramenta de preservação ambiental, especialmente de matas ciliares e biodiversidade, precisa contemplar uma percepção sistêmica, indispensável à construção da racionalidade ecológica. Por esse motivo, muitos dos programas em desenvolvimento no Brasil carecem de periódica revisão e incessante perseguição dos objetivos socioambientais, de modo a avançar na construção de uma possível racionalidade ambiental.

\section{CONSIDERAÇÕES FINAIS}

O Estado utiliza-se de instrumentos de comando e controle (imposição de standards, limites, padrões e proibições), bem como de instrumentos econômicos (cobrança pelo uso da água; ICMS ecológico; Pagamento por Serviços Ambientais; seguros ambientais; concessão florestal; servidão ambiental; royalties; etc) com a finalidade de corrigir as distorções e injustiças socioambientais provocadas pelo mercado econômico. No Brasil, os instrumentos de regulação ambiental estão situados principalmente na Constituição Federal (art. 225) e Lei da Política Nacional do Meio Ambiente (Lei nº.6.938/1981).

Dentre os instrumentos econômicos, a pesquisa em comento destacou o Pagamento por Serviços Ambientais (PSA), espécie de transação voluntária que envolve a "remuneração daqueles que promovem a conservação, 
recomposição, incremento ou manejo de áreas de vegetação considerada apta a fornecer certos serviços ambientais". Nesse sentido, distinguiram-se os serviços ecossistêmicos dos ambientais, já que aqueles designam os serviços prestados pelos ecossistemas (purificação do ar, ciclo hidrológico, polinização, regulação do clima, etc), enquanto que estes implicam as atitudes ambientalmente desejáveis que contribuem à concretização das externalidades positivas.

Na última década, múltiplos programas de PSA difundiram-se pelo Brasil de forma inédita com o escopo de "resolverem" problemas específicos locais. Ainda que não haja um marco legal federal regulamentador do instituto, diversas são as experiências com o PSA e distintos os formatos e modelos do seu desenvolvimento.

A valoração econômica ambiental é relevante para problematizar a natureza no círculo da ciência econômica com vistas a melhor garantir a internalização dos custos socioambientais nas atividades humanas, como elucidado, principalmente, nos trabalhos de Arthur Pigou. Contudo, em termos de programas de PSA, a depender do seu contexto, objetivos, protagonismo, público-alvo e finalidades, lapidou-se que o instituto acaba aferindo valores aos custos de oportunidade do provedor do serviço ambiental e não meramente "monetarizando" a natureza, tal como sustentado pelos críticos do instrumento.

Construídas essas premissas, ressaltou-se que os Programas de PSA, geralmente liderados pelo Poder Público, controlam com maior efetividade a tendência econômica de criarem-se mercados específicos para a demanda de serviços ambientais. Por isso, discutiu-se a viabilidade de determinados projetos de PSA atrelarem-se ao mote da racionalidade ambiental, em vista de muitos programas mobilizarem e fortalecerem a pluralidade, as economias locais e a mudança de consciência ecológica sobre as práticas e comportamentos nos ecossistemas.

\section{REFERÊNCIAS}

ALIER, Joan Martínez. O ecologismo dos pobres. São Paulo: Contexto, 2014.

ALTMANN, Alexandre. Pagamento por serviços ambientais urbanos como instrumento de incentivo para os catadores de materiais recicláveis no Brasil. Revista de Direito Ambiental, São Paulo, v. 68, p. 307, out. 2012. 
ALTVATER, Elmar. O preço da riqueza. São Paulo: Ed. UNESP, 1995.

ARAGÃO, Alexandre Santos de. Agências reguladoras e a evolução do direito administrativo econômico. Rio de Janeiro: Forense, 2004.

BRASIL. Ministério do Meio Ambiente. Instrumentos econômicos.

Disponível em: $<$ http://www.mma.gov.br/cidades-sustentaveis/planejamentoambiental-urbano/instrumentos-econ\%C3\%B4micos>. Acesso em: 24 mar. 2014.

CAMPOS, Humberto Alves. Instrumentos econômicos na gestão ambiental brasileira. Revista de Direito Ambiental, São Paulo, v. 63, p. 287-303, Jul./ 2011.

DERANI, Cristiane. Direito ambiental econômico. 2. ed. São Paulo: Max Limonad, 1997.

EXTREMA. Prefeitura Municipal. Projeto "Conservador das Águas". 2010. Disponível em: $<$ http://extrema.mg.gov.br/conservadordasaguas/LivroConservador-20101.pdf>. Acesso em: 21 mar. 2014.

FOLADORI, Guillermo. Limites do desenvolvimento sustentável. Campinas: Ed. Unicamp, 2001.

GUEDES, Fátima Becker; SEEHUSEN, Susan Edda (Org.). Pagamentos por serviços ambientais na mata atlântica: lições aprendidas e desafios. Brasília: Ministério do Meio Ambiente, 2011.

IRIGARAY, Carlos Teodoro José Hugueney. O emprego de instrumentos econômicos na gestão ambiental. In: LEITE, José Rubens Morato; BELLO FILHO, Ney de Barros. Direito ambiental contemporâneo. Barueri: Manole, 2004. p. 51-74.

KAPP, Karl William. The social costs of private enterprise. Cambrige: Harvard University Press, 1950.

LAVRATTI, Paula (Org.). Sistemas estaduais de pagamento por serviços ambientais. Diagnóstico, lições aprendidas e desafios para a futura legislação. São Paulo: Instituto o Direito por um Planeta Verde, 2014. 
LEFF, Enrique. Discursos sustentáveis. São Paulo: Cortez, 2010.

MONTERO, Carlos Eduardo Peralta. Extrafiscalidade e meio ambiente: o tributo como instrumento de proteção ambiental. Reflexões sobre a tributação ambiental no Brasil e na Costa Rica. 2011. 304f. Tese (Doutorado em Direito) - Universidade Estadual do Rio de Janeiro - UERJ, Rio de Janeiro, 2011.

MOTA, José Aroudo. O valor da natureza: economia e política dos recursos naturais. Rio de Janeiro: Garamond, 2001.

NUSDEO, Ana Maria de Oliveira. O uso de instrumentos econômicos nas normas de proteção ambiental. Revista da Faculdade de Direito da Universidade de São Paulo, São Paulo, v. 101, p. 357-378, jan./dez. 2006.

. Pagamento por serviços ambientais. Sustentabilidade e disciplina jurídica. São Paulo: Atlas, 2012.

. Pagamento por serviços ambientais: comentários sobre sua implementação no Brasil. In: LEITE, José Rubens Morato; PERALTA, Carlos E. Perspectivas e desafios para a proteção da biodiversidade no Brasil e na Costa Rica. São Paulo: Instituto o Direito por um Planeta Verde, 2014. p. 415-437.

\section{ORGANIZAÇÃO DAS NAÇÕES UNIDAS. Declaração do Rio sobre} meio ambiente e desenvolvimento. 1992. Disponível em: <http:// www.mma.gov.br/port/sdi/ea/ documentos/convs/decl_rio92.pdf $>$. Acesso em: 24 mar. 2014.

ORTIZ, Ramon Arigoni. Valoração econômica ambiental. In: MAY, Peter H.; LUSTOSA, Maria Cecília; VINHA, Valéria de. Economia do meio ambiente. Rio de Janeiro: Elsevier, 2003. p. 81.

PADOVEZI, Aurélio; DIEDERICHSEN, Anita; VEIGA, Fernando (Org.). Projeto conservador das águas passo a passo. Brasília: The Nature Conservancy do Brasil, 2011. (Série Água, Clima e Floresta, v. 4). 
PIGOU, Arthur C. The economics of welfare. 1959. Disponível em: $<$ http:// www.econlib.org/library/NPDBooks/Pigou/pgEW0.html>.

Acesso em: 21 mar. 2014.

WALDMAN, Ricardo Libel; ELIAS, Luiz Augusto da Veiga. Os princípios do direito ambiental e o pagamento por serviços ambientais/Ecossistêmicos (PSA/PSE). Revista de Direito Ambiental, São Paulo, v. 69, p. 53-73, jan. 2013.

WUNDER, Sven. Pagos por servicios ambientales: princípios básicos esenciales. Jakarta: Centro Internacional de Investigación Florestal (CIFOR), 2006.

Submetido em: 27/01/2015 Aprovado em: 20/04/2015

Como citar: DERANI, Cristiane; JODAS, Natália. Pagamento por serviços ambientais (PSA) e a racionalidade ambiental: aproximações. Scientia Iuris, Londrina, v19, n.1, p.9-27, jun.2015. 